\title{
An educational game on the theories of driver education curriculum: An evaluation
}

\author{
Zainab Othman', Nurul Hidayah Mat Zain², Ismassabah Ismail ${ }^{3,}$ Sharifah Nor Syasya Syed Mohd \\ Affandi $^{4}$, Nor Azida Mohamed Noh ${ }^{5}$, Anita Mohd Yasin ${ }^{6}$ \\ ${ }^{1,2,4,5,6}$ Faculty of Computer and Mathematical Sciences, Universiti Teknologi Mara, Malaysia \\ ${ }^{3}$ Centre of Foundation Studies, Universiti Teknologi Mara, Malaysia
}

\section{Article Info}

Article history:

Received Apr 9, 2020

Revised Sep 20, 2020

Accepted Oct 12, 2020

\section{Keywords:}

Driver education curriculum

Educational game

Game-based learning

\begin{abstract}
The purpose of this study was to evaluate the effectiveness of using an educational game application among driving school students on their understanding of driving rules and regulations. The application was developed and named as An Educational Game on the Theories of Driver Education Curriculum (DEC) to help students improve their visualization, understanding and memorization of the theories of driving rules and regulations as well as to be more prepared before taking the driving theory test. A preliminary study was conducted and it indicated that students had a hard time in visualizing, understanding and memorizing the theories of driving. The Game Development Life Cycle (GDLC) was implemented as a methodology to develop the DEC application which consists of initiation, pre-production, production, testing, beta, and release phases. The effectiveness of the DEC application was measured by Game-Based Learning Evaluation Model (GEM). The findings indicated that educational game helped students to visualize, memorize and understand the theories of driving easily.
\end{abstract}

This is an open access article under the CC BY-SA license.

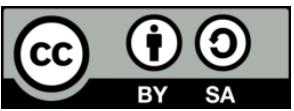

\section{Corresponding Author:}

Zainab Othman,

Faculty of Computer and Mathematics,

Universiti Teknologi Mara,

Kampus Jasin, 77300 Jasin Melaka, Malaysia.

Email: zainab_othman@uitm.edu.my

\section{INTRODUCTION}

Nowadays, people tend to commute to places using their private vehicles more than using public transportation [1]. In order to drive their vehicles, they must possess a legal driving license by taking the Driver Education Curriculum (DEC) course. They have to pass the theoretical test of safe driving through computerized testing before they can be practically trained on the road [2]. The candidates must attend several hours of lecture regarding the theories of safe driving in DEC [3], and they must have the DEC textbook as a guideline to become a safe driver [4].

However, using only the DEC textbook to prepare for the computer test does not give them enough visualization to understand and memorize the theories. Udjaja, et al. [5] said that a particular learning style of an individual depends on how they think, feel, hear and practice. When someone thinks and feels something as unattractive, then learning will be easily forgotten. Research by Novota, et al. [6] found that university students considered that many textbooks are hard to understand. Besides, the existing applications regarding the theories of DEC in the online platform stores are only in the form of quizzes, where the questions and answers are in text-based and lack of visualization. This problem regarding the lack of visualization may 
affect the effectiveness of the DEC theories learnt by the candidates. This statement is supported by the study of Chittaro [7] who reported that the effectiveness of an application could be contributed by its visualization aspect. Also, according to the survey that was conducted on those who had taken the computer test before, $66.7 \%$ of them agreed that the DEC textbook provided lacks visualization and $60 \%$ of them agreed that they had a hard time in understanding and memorizing the theories of DEC respectively. Furthermore, a research by Chittaro [7] on an application found that the users gave positive feedback on the visualization provided in the application because it was easier to understand the contents.

One of the approaches to improve the learning of the DEC theories is using the Game-Based Learning Model as designing and learning indicator. Furthermore, the educational game genre was chosen as it is more suitable for educating the users on the theories of the DEC. All features of the educational game do not only teach and help learner to memorize the facts but also serves as an edutainment tool.

This paper presents the evaluation of the effectiveness of using the Educational Game on the Theories of Driver Education Curriculum by using Game-Based Learning Evaluation Model (GEM). The questionnaires had been modified to suit the Malaysian requirements using the Malay language. The evaluation was conducted for people aged between 17 to 21 years old who had never taken the computer test before for the driving license, and this is the legal age to take a driving license for class D in the country. The purpose of this evaluation is to show that an educational game can help students to learn the theories of driving efficiently. It also shows that it was an effective application to improve the user's understanding and memorization of the theories of driving.

\section{LITERATURE REVIEW}

The DEC is a formal class or program that prepares a new driver to receive a legal driving license. It is formulated to help drivers or road users to master the aspects of safety and regulations that need to be practised on the road. There are three phases of the test in the DEC before the candidates obtain their driving license. The first phase is the theoretical test through a computerized testing regarding the theories of safe driving, which is to test the candidates' level of comprehension on the traffic rules and regulations. The second phase is to test the candidates' skills in controlling the vehicle while driving. Lastly, the candidates will be driving on the real road situations to test the ability of the candidates to apply the safe driving theories learnt in the first phase supervised by a legal driving instructor [3].

There are three types of driving license which are Learner's Driving License (LDL), Probationary Driving License (PDL) and Competence Driving License (CDL). Passing the first phase will allow the candidates to obtain an LDL, whereas passing the second and third phases will allow them to obtain a PDL. PDL will expire after two years and be upgraded to CDL. These three types of driving licence are placed under the DEC program. However, the current DEC program lacks of visualization in understanding and memorizing the theories.

Visualization plays a significant effect on memory, as stated by Kosara and Mackinlay [8] in their article. So, when there is a lack of visualization of the DEC theories, it will be harder for the candidates to memorize the theories. The study was supported by the survey done in the preliminary study, where $80 \%$ of the respondents agreed that they had a hard time in memorizing for the computerized test. Thus, this educational game was designed to add visualization to improve the effectiveness of the theories learnt; it is much easier for the candidates to understand and memorize the theories.

\subsection{Game-based learning}

GBL is an e-learning platform that can encourage learners to enhance motivation in learning through game playing experience and as methodology to support effective learning [9, 10]. GBL is developed intended to teach a subject through software that can be run on computers; for instance, laptop, desktop, handheld, or game console [11]. There are various subjects used GBL such as learning basic mathematic through 'congkak' [12], learning biology [13], learning the Arabic language [14] and learning linear algebra [15]. A research by Connoly [16] stated that GBL is using computer game-based approach to convey, support, and improve learning, teaching, assessment, and evaluation. According to references [17, 18], GBL is an e-learning platform that can encourage learners to enhance motivation in learning through game playing experience. Based on an article by Mohamed, et al. [19], effective learning is improved when the learner interacts actively within the game, experiences a balance of challenges and possible action courses and mentally involved in the game. GBL gives the learner a platform to learn through experience and knowledge acquisition. The combination of these two is usually more efficient than learning by just studying. According to Ida, et al. [20], the game has been recognized by the educational theories and researchers as potential resources in the learning process. Besides, a GBL approach is an effective method to leadership skills 
growth, which the main skills developed were: motivation, facilitation, coaching, mindset changing, and communication [21].

\subsection{Game-based learning models}

Many different models can be used as a guideline in developing a GBL. Some of the models are GameFlow Model, Game-Based Learning Evaluation Model (GEM) and Game Object Model (GOM). The GEM model was implemented as an indicator to evaluate the effectiveness of the usage of a serious game in education [22]. These indicators help in evaluating the game's effectiveness before (pre-test), during and after (post-test) playing the game. Design indicators are related to the evaluation of during the gameplay and the game such as Action Language, Feedback, Challenge, Control, Rules and Goals and Game Worlds. Whereas learning indicators are related to evaluation before and after the gameplay to measure the learning outcome that the user had gained from playing the game such as Self-Efficacy and Engagement/Motivation. Both indicators are shown in Table 1 and Table 2 respectively. Yedri, et al. [23] reported that serious games attract the attention of students and professionals in many areas including business, economy, education, health care, politic, manufacturing, scientific, medicine, and tourism.

Table 1. Elements of design indicators

\begin{tabular}{cl}
\hline Design indicators & \multicolumn{1}{c}{ Explanation } \\
\hline Action language & $\begin{array}{l}\text { A method where the game interface allows the player to interact with [24]. } \\
\text { Feedback from the game to inform the player on the progress of the game [25]. For example, } \\
\text { scores, hints and achievements. } \\
\text { Game content where the player faces problems [22] and the challenge should match the player's } \\
\text { skill level [25]. } \\
\text { The player's control of the gameplay or content and the player's scope for effect over the game } \\
\text { elements [26] and allow the player to manipulate the game world [27]. }\end{array}$ \\
Control & $\begin{array}{l}\text { Rules are a method used by the player to solve problems to reach the goals of the game. } \\
\text { Related to the context of the game and the game environment such as the narration, location, role } \\
\text { of player and it could be realistic or fantasies [28]. }\end{array}$ \\
\hline
\end{tabular}

Table 2. Elements of learning indicators

\begin{tabular}{cl}
\hline Learning Indicators & \multicolumn{1}{c}{ Explanation } \\
\hline Self-efficacy & $\begin{array}{l}\text { Individuals' beliefs or learner's confidence in their performance capabilities and ability to } \\
\text { perform the task [29]. } \\
\text { Motivation/Engagement } \\
\text { Learner's engagement and concentration towards the subject matter [30] and the person's } \\
\text { active involvement in a task [31]. }\end{array}$ \\
\hline
\end{tabular}

\section{RESEARCH METHOD}

The development of this application was based on the Game Development Life Cycle (GDLC). It consists of six phases which are initiation, pre-production, production, testing, beta and release phases. GDLC was chosen because it uses the iterative approach, where it enables a higher degree of flexibility to changes. If there are bugs and errors found in the testing phase, it can iterate back to the pre-production phase to make improvements until it is ready for beta testing. Moreover, the cost to fix the bugs and errors are less expensive because it is going through the iterative process.

The concept of this game is like driving a car on the actual road where the player will be navigating a car using keypress, and they will have to reach the desired score to unlock the next level. Along the way, the player will have to answer questions regarding the theories of the DEC by choosing the correct path or answering the right questions. Marks will be given for the correct answers. The player can only make three mistakes before the game is over and they would have to restart the game. Also, the correct answer will be displayed if they chose the wrong answer so that they can learn from their mistakes. The environment will be on the road, and the player will be controlling a car.

Internal testing was conducted to test whether the game functions correctly. The aspects that will be tested are the game functionality and difficulty via playtesting, and the game accessibility is tested to see if the game is easy to be understood by the user. If the game is challenging to play and understand, then it means the game is not accessible enough. At the end of the testing, the bug is reported. The analysis is made whether to re-iterate the production cycle to make improvements or proceed to the next phase. There are two types of methods in beta testing, which are closed beta and open beta. The closed beta allows only one selected person to become the tester, while open beta allows anyone who registers to become the tester. The closed beta was chosen as the method since the testers must be individuals who have not taken the computer test for the DEC, and the evaluation will be based on the GEM model. This is to determine whether this game 
achieves the objective, which is the effectiveness of using an educational game to learn driving rules and regulations. Table 3 and Table 4 show the scale of GEM created based on the design and learning indicators.

Table 3. The scale of GEM on the game design

\begin{tabular}{ccc}
\hline Factors & Item No. & Contents \\
\hline & C1 & This game is appropriately challenging for me; the tasks are not too easy nor too difficult \\
Challenge & C2 & $\begin{array}{l}\text { The game progresses at an adequate pace and does not become monotonous - offers new } \\
\text { obstacles, situations or variations in its tasks } \\
\end{array}$ \\
& C3 & The game provides hints that help me to overcome the challenges \\
& C4 & The game provides audio and video auxiliaries to help me overcome the challenges \\
& C5 & The game provides new challenges with an appropriate pacing \\
Feedback & F2 & I receive feedback on my progress in the game \\
& F3 & I receive information on my success or failure of intermediate goals immediately \\
& F4 & I am notified of new events immediately \\
Rules and & R1 & Overall game goals are presented at the beginning of the game \\
Goals & R2 & Overall game goals are presented clearly \\
& R3 & Intermediate goals are presented clearly \\
Game & R4 & Intermediate goals are presented at the beginning of each scene \\
Worlds & G1 & The game world is simple and visible enough \\
Control & H1 & The game is easy for me to navigate \\
\end{tabular}

Table 4. The scale of GEM on the learning

\begin{tabular}{ccl}
\hline Factors & Item No. & \multicolumn{1}{c}{ Contents } \\
\hline \multirow{4}{*}{ Self-efficacy } & S1 & Passing through the game, I felt confident that I was learning \\
& S2 & I believe I will receive an excellent grade for my computer test after playing the game \\
& S3 & I am confident I can understand the basic concepts of the theories of DEC \\
& S4 & I am certain I can understand the most difficult materials regarding the theories of DEC \\
& S5 & I am certain I can master the theories of DEC \\
Motivation/Engagement & M1 & The variation (form, content or activities) helped me to keep attention to the game \\
& M3 & The game content is connected to other knowledge I already have \\
& & The game enhances curiosity in order for us to keep playing
\end{tabular}

\section{APPLICATION DESIGN}

GEM Model is used to evaluate the effectiveness of an application. There are two types of related indicators in GEM, which are design and learning indicators to be used in the evaluation. The elements in the design indicators are action language, feedback, challenge, control, rules \& goals, and game worlds. Table 5 shows the implementation of elements in GEM Model and its explanations. 
Table 5. Implementation and explanation of the elements of the GEM model

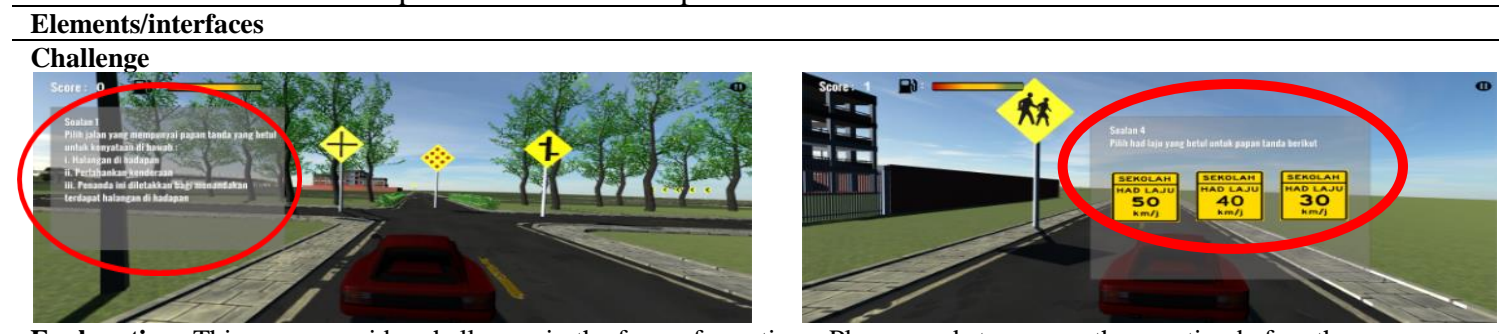

Explanation: This game provides challenges in the form of questions. Player needs to answer the question before they can proceed to the next one and complete the level. If they answered wrongly, the fuel level would decrease. They are only given three chances before the fuel is empty and game will be over. In order to proceed to the next level, the player needs to achieve a full mark for the current level.
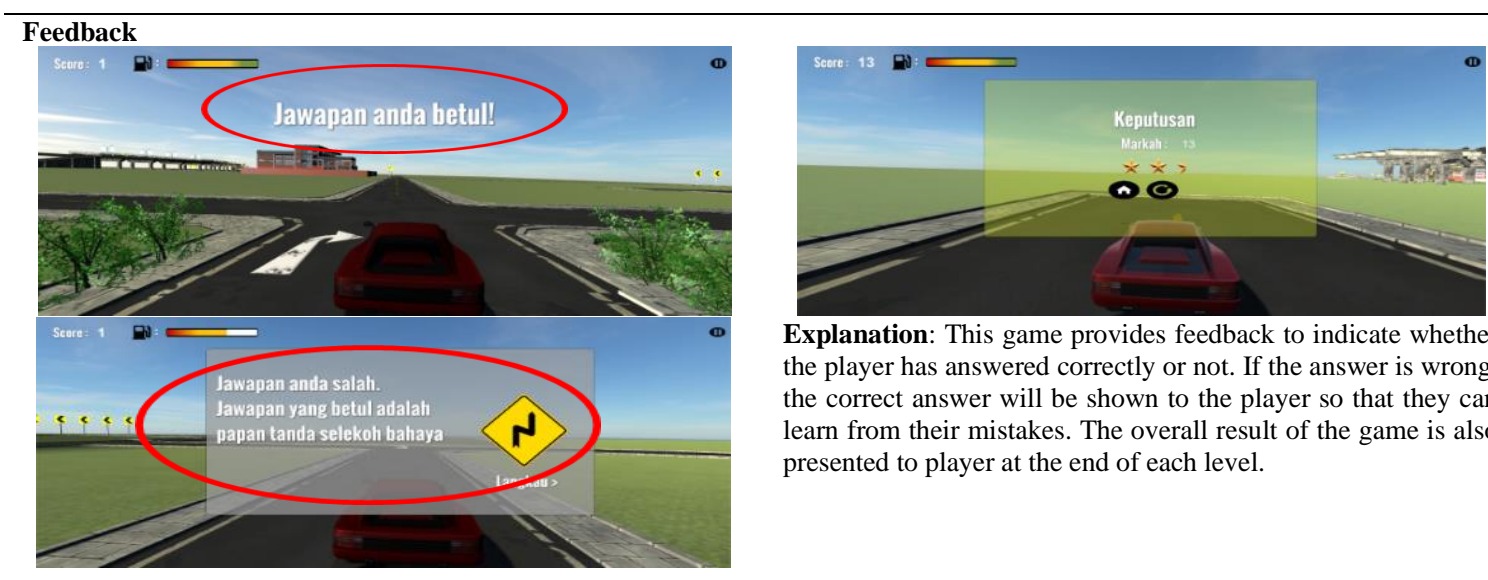

Explanation: This game provides feedback to indicate whether the player has answered correctly or not. If the answer is wrong, the correct answer will be shown to the player so that they can learn from their mistakes. The overall result of the game is also presented to player at the end of each level.
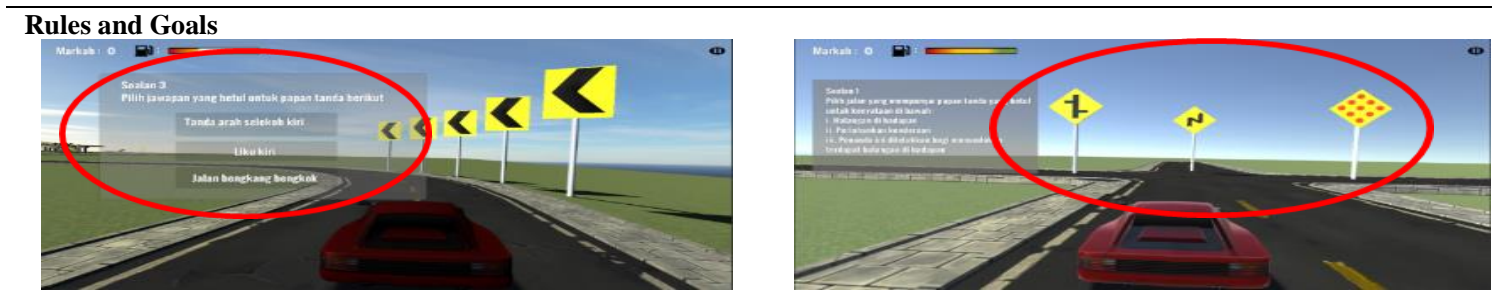

Explanation: Rules are a method used by the player to solve problems to reach the goals of the game. In this game, there are two methods that can be used to answer the questions. The first method is they can choose the answer by clicking on the answer button and the second method is by choosing the correct path.

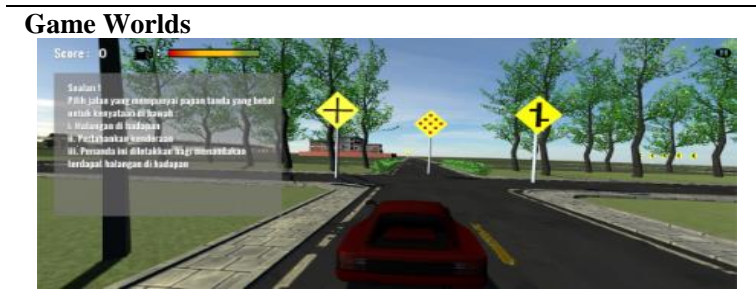

\section{Explanation:}

The environment of this game is realistic as it imitates the real road situations and locations such as highways, slopes and housing areas. The player will act as the driver that drives the car along the road while answering questions regarding the theories of DEC.
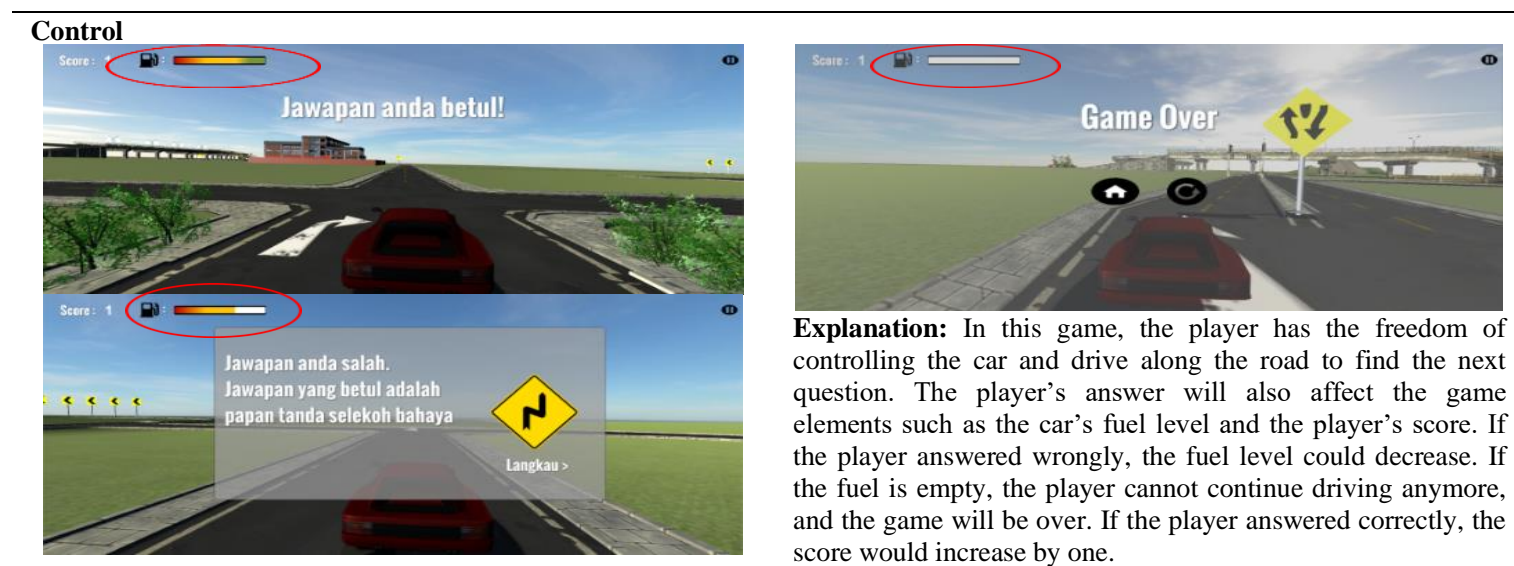

Explanation: In this game, the player has the freedom of controlling the car and drive along the road to find the next question. The player's answer will also affect the game elements such as the car's fuel level and the player's score. If the player answered wrongly, the fuel level could decrease. If the fuel is empty, the player cannot continue driving anymore, and the game will be over. If the player answered correctly, the score would increase by one. 


\section{RESULTS AND DISCUSSION}

The evaluation was conducted on the target users who were individuals without a driving license and had never taken the computer test before. The respondents were divided into two groups which were control group and experimental group. The experimental group was the group that studied the teories of DEC by playing the game application while the control group studied using the DEC textbook only. Both groups answered the pre-test and post-test questions to evaluate their understanding and memorization of the theories of DEC. This result would further support this game's effectiveness to the user. A Likert-Scale [32] was used to determine the average value accumulated based on the GEM model. For the beginning, both groups were given the same set of pre-test questions on their basic knowledge. Then, they were given a week to study the theories of DEC using notes for the control group and using this game for the experimental group. After that, they were given a post-test. Based on Table 6 , the result on the assessments, post-test minus pre-test were calculated and analyzed to investigate the differences in the advancement of their knowledge. It was indicated that the average result for the experimental group was significantly higher than the average result for the control group which was $20.93 \%$ and $11.6 \%$ respectively. The findings show the participants who learned the theories of DEC through the game had a better understanding and memorizing compared to those who read the DEC textbook. It was supported by $[33,34]$ where memorizing using the game is better than read the DEC textbook and have fun activities because it involved interactivity, thinking, learning and strategies.

The evaluation of questionnaires as listed in Table 3 and Table 4 had its own mean values to determine which criteria have the highest percentage of agreedability of user. The total mean of the design indicators will determine whether this game is effective or not and the total mean of learning indicators will determine what the user felt the most after learning through this game.

Table 6. Pre-test and post-test results and its mean values

\begin{tabular}{|c|c|c|c|c|c|c|}
\hline & \multicolumn{3}{|c|}{ Control Group } & \multicolumn{3}{|c|}{ Experimental Group } \\
\hline & $\begin{array}{c}\text { Pre-test } \\
(\%)\end{array}$ & $\begin{array}{c}\text { Post-test } \\
(\%)\end{array}$ & $\begin{array}{c}\text { (Post-test) - } \\
\text { (Pre-test) (\%) }\end{array}$ & $\begin{array}{c}\text { Pre-test } \\
(\%)\end{array}$ & $\begin{array}{c}\text { Post-test } \\
(\%)\end{array}$ & $\begin{array}{c}\text { (Post-test)- } \\
\text { (pre-test) }(\%)\end{array}$ \\
\hline Participant 1 & 66 & 74 & 8 & 56 & 82 & 26 \\
\hline Participant 2 & 60 & 68 & 8 & 70 & 88 & 18 \\
\hline Participant 3 & 54 & 84 & 30 & 70 & 96 & 26 \\
\hline Participant 4 & 68 & 78 & 10 & 66 & 90 & 24 \\
\hline Participant 5 & 64 & 82 & 18 & 74 & 78 & 4 \\
\hline Participant 6 & 76 & 88 & 12 & 68 & 94 & 26 \\
\hline Participant 7 & 78 & 90 & 12 & 64 & 94 & 30 \\
\hline Participant 8 & 68 & 76 & 8 & 58 & 84 & 26 \\
\hline Participant 9 & 68 & 74 & 6 & 76 & 82 & 6 \\
\hline Participant 10 & 58 & 70 & 12 & 62 & 92 & 30 \\
\hline Participant 11 & 66 & 74 & 8 & 74 & 84 & 10 \\
\hline Participant 12 & 66 & 76 & 10 & 66 & 78 & 12 \\
\hline Participant 13 & 60 & 72 & 12 & 54 & 80 & 26 \\
\hline Participant 14 & 56 & 70 & 14 & 70 & 96 & 26 \\
\hline Participant 15 & 74 & 80 & 6 & 62 & 86 & 24 \\
\hline Mean & & & 11.6 & & & 20.93 \\
\hline
\end{tabular}

\subsection{Design indicators}

Based on Table 7, for the evaluation challenge factor, the highest voted question was "agreeability on the game provides new challenges with an appropriate pacing (C5)" with the average mean of 3.79. In the feedback evaluation, the most selected question was "the player agreed that they receive immediate feedback on the progress in the game (F2)" with the average mean of 4.29. There were two most voted questions in Rules and Goals were "overall game goals were presented at the beginning of the game (R1) and Intermediate goals were presented clearly (R2)" with the average mean of 4.47 . The most voted question in Game Worlds Criteria was "the game was easy to navigate (G2)" with the average mean of 4.4. There was one question in the Control evaluation which is "the game is easy to use (H1)" with the average mean of 3.93. The overall average mean is $84 \%$. It was proven by [35], for effective learning environment, it must be provided with the basic requirements, including providing students certain tasks with clear goals, challenges, achieving a high degree of interaction and feedback and control. 
Table 7. Overall mean of design indicators

\begin{tabular}{cllrrr}
\hline Criteria & & & Item/Total mean & Average mean \\
\hline Challenge & C1(3.73) & C2 (3.87) & C3 (3.60) & C4 (3.60) & C5 (4.15) \\
Feedback & F1 (4.60) & F2 (4.67) & F3 (3.60) & 4.79 \\
Rules and Goals & R1 (4.60) & R2 (4.20) & R3(4.60) & 4.47 \\
Game Worlds & G1 (4.13) & G2 (4.67) & & 4.40 \\
Control & H1 (3.93) & & & 3.93 \\
Average Mean and Percentage & & & & $4.18(84 \%)$ \\
\hline
\end{tabular}

\subsection{Learning indicators}

Based on Table 8, the highest average mean was on self-efficacy and motivation with the values of 4.21 and 4.04 respectively. The findings indicated that after playing and learning through this game, the user's beliefs and confidence in learning the DEC theories had increased. This is supported by [36] where when the self-efficacy is higher, players are more likely to engage in the game.

The overall average mean of both design and learning indicators were calculated, and the result showed a value of $4.18(84 \%)$ and $4.13(83 \%)$ respectively. The result showed that more than half of the respondents agreed that this game was effective for them to learn the theories of DEC through this educational game.

Table 8. Overall mean of learning indicators

\begin{tabular}{cccccc}
\hline Criteria & \multicolumn{3}{c}{ Item/Total mean } & Average mean \\
\hline Self-Efficacy & C1 (4.20) & C2 (4.60) & C3 (4.47) & C4 (3.80) & C5 (4.00) \\
Motivation/Engagement & F1 (4.00) & F2 (4.07) & & 4.21 & 4.04 \\
Average Mean and Percentage & & & & $4.13(83 \%)$ \\
\hline
\end{tabular}

\section{CONCLUSION}

The Educational Game on the Theories of Driver Education Curriculum is developed to improve user's visualization, understanding and memorization of the theories of the driving rules and regulations before taking the driving theory test using the GEM Model. From the comparative studies among the control group and experimental group, it was found that this educational game was an effective application to improve their understanding and memorization. Besides, the feedback evaluation received indicated that the students preferred to play this game as one of the learning methods rather than entirely depending on the DEC textbook. It shows that this educational game was suitable for educating the students on the theories of driving rules and regulations.

\section{REFERENCES}

[1] O. Chiu Chuen, M. R. Karim, and S. Yusoff, "Mode choice between private and public transport in Klang Valley, Malaysia," Sci. World J., vol. 2014, pp. 7-9, 2014. [Online]. Available: https://doi.org/10.1155/2014/394587

[2] Z. M. Jawi, et al., "A systemic overview on driver training and driver licensing system in Malaysia," in Proceedings Conference ASEAN Road Safety, pp. 185-191, 2015.

[3] Kurikulum Pendidikan Pemandu Kelas D Manual, $2^{\text {nd }}$ edition. Institut Memandu di Malaysia, 2016.

[4] Z. M. Jawi, M. K. Rahman, and M. K. A. Ibrahim, "Status Report of the Driving Institute in Malaysia (in Malay)," 2011.

[5] Y. Udjaja, V. S. Guizot, and N. Chandra, "Gamification for elementary mathematics learning in Indonesia," Int. J. Electr. Comput. Eng., vol. 8, no. 5, pp. 3859-3865, 2018.

[6] M. Novota, et al., "Secondary schools graduates' attitude towards textbooks for vocational education," Int. J. Vocation and Tech. Edu., vol. 4, no. 2, pp. 25-28, 2012.

[7] L. Chittaro, "Visualizing information on mobile devices," Computer (Long. Beach. Calif), vol. 39, no. 3, pp. 40-45, 2006.

[8] R. Kosara and J. MacKinlay, "Storytelling: The next step for visualization," Computer (Long. Beach. Calif), vol. 46, no. 5, pp. 44-50, 2013.

[9] T. M. Connolly, et al., "A systematic literature review of empirical evidence on computer games and serious games," Comput. Educ., vol. 59, no. 2, pp. 661-686, 2012.

[10] P. Wouters, et al., "A meta-analysis of the cognitive and motivational effects of serious games," J. Educ. Psychol., vol. 105, no. 2, pp. 249-265, 2013.

[11] S. Aslan and O. Balci, "GAMED: digital educational game development methodology," Simulation, vol. 91, no. 4, pp. 307-319, 2015. 
[12] A. Jelani, H. Hasrol, and I. Ismail, "Enjoyment of Learning Basic Math Through Congkak Game-Based Learning" in Information, Communication and Multimedia Technology Colloq. (ICMMTC), Melaka, Malaysia, vol. 1, pp. 156-162, 2018.

[13] S. Rozaidi and I. Ismail, "Enjoyment of learning biology through mobile game based learning for form 5 students: Kidney rush," in Information, Communication and Multimedia Technology Colloq. (ICMMTC), Melaka, Malaysia, vol. 1, pp. 163-170, 2018.

[14] A. Amri, M. Hasnan, and I. Ismail, "Mezbic:Learn Arabic Language Through Maze Escape Mobile Game for UiTM Students," in Information, Communication and Multimedia Technology Colloq. (ICMMTC), Melaka, Malaysia, vol. 1, pp. 268-275, 2018.

[15] R. Rahim, A. Baharum, and H. Hijazi, "Evaluation on effectiveness of learning linear algebra using gamification," Indones. Journal Electr. Eng. Comput. Sci., vol. 17, no. 2, pp. 997-1004, 2020.

[16] T. M. Connolly, et al., "An application of games-based learning within software engineering," Br. J. Educ. Technol., vol. 38, no. 3, pp. 416-428, 2007.

[17] C.-S. Wang, C.-C. Liu, and Y.-C. Li, "A game-based learning content design framework for the elementary school children education," in The 16th North-East Asia Symposium on Nano, Information Technology and Reliability, pp. 53-57, 2011.

[18] Prensky, et al., "Digital game-based learning" Computers in Entertainment, vol. 1 no. 1, pp. 1-26, 2003.

[19] N. A. M. Masrop, et al., "Digital Games Based Language Learning for Arabic Literacy Remedial," Creat. Educ., vol. 10, no. 12, p. 3213, 2019.

[20] I. S. Sudin, et al., "Adaptation meta-cognitive as an educational tool: Animated puzzle," Indones. J. Electr. Eng. Comput. Sci., vol. 12, no. 1, pp. 319-325, 2018.

[21] M. J. Sousa and Á. Rocha, "Leadership styles and skills developed through game-based learning," J. Bus. Res., vol. 94, pp. 360-366, Jan. 2019.

[22] E. Oprins, et al., "The game-based learning evaluation model (GEM): Measuring the effectiveness of serious games using a standardised method," Int. J. Technol. Enhanc. Learn., vol. 7, no. 4, pp. 326-345, 2015.

[23] O.B. Yedri, L. El Aachak and M. Bouhorma, "Assessment-driven Learning through Serious Games: Guidance and Effective Outcomes," International Journal of Electrical and Computer Engineering, vol. 8, no. 5, p. 3304, 2018.

[24] W. L. Bedwell, et al., "Toward a taxonomy linking game attributes to learning: An empirical study," Simul. Gaming, vol. 43, no. 6, pp. 729-760, 2012.

[25] P. Sweetser and P. Wyeth, "GameFlow: a model for evaluating player enjoyment in games," Comput. Entertain., vol. 3, no. 3, p. 3, 2005.

[26] R. Garris, R. Ahlers, and J. E. Driskell, "Games, motivation, and learning: A research and practice model," Simul. Gaming, vol. 33, no. 4, pp. 441-467, 2002.

[27] J. P. Gee, "What video games have to teach us about learning and literacy," Comput. Entertain., vol. 1, no. 1, p. 20, 2003. [Online]. Available: https://doi.org/10.1145/950566.950595

[28] A. Graesser, P. Chipman, and F. Leeming, "Deep learning and emotion in serious games," in Serious Games. Routledge, pp. 105-124, 2009.

[29] A. Bandura, et al., Self-efficacy: The exercise of control. Springer, 1999.

[30] J. L. Plass, et al., "Foundations of game-based learning," Educ. Psychol., vol. 50, no. 4, pp. 258-283, 2015.

[31] J. Reeve, et al., "Enha ncing students' engagement by increasing teachers' autonomy support," Motiv. Emot., vol. 28 , no. 2, pp. 147-169, 2004.

[32] I. Allen and C. Seaman, "Likert scales and data analyses," Quality progress., vol. 40, no. 7, pp. 64-65, 2007.

[33] E. Akdogan, "Developing Vocabulary in Game Activities and Game Materials," Journal of Teaching and Education, vol. 07, no. 1, pp. 31-66, 2017.

[34] B. E. Martinson and S. Chu, "Impact of learning style on achievement when using course content delivered via a game-based learning object," in Handbook of research on effective electronic gaming in education. IGI Global, 2008 .

[35] K. Salen, K. S. Tekinbaş, and E. Zimmerman, Rules of play: Game design fundamentals. MIT Press, 2004.

[36] D. Eseryel, et al., "An investigation of the interrelationships between motivation, engagement, and complex problem solving in game-based learning," Educ. Technol. Soc., vol. 17, no. 1, pp. 42-53, 2013. 